\title{
The Development of a Framework for Assessing Developing Conversational Skills
}

\author{
Susan Rumble, B.Sc. (Log) (Cape Town) \\ Hearing and Speech Clinic, \\ Tygerberg Hospital \\ Karen Malan, M.A. (Appl. Linguistics) (Reading, U.K.) \\ Department of Logopaedics, \\ University of Cape Town
}

\begin{abstract}
A framework for investigating the development of conversational skills in children, comprising the areas of topic control, repair of communication breakdown and linguistic cohesion, was devised. This was undertaken by a process of collating information from some existing pragmatic profiles and the developmental literature. The framework was then modified inductively to accommodate features of the data obtained from 12 normally developing English-speaking children in the age groups three, four and five years. A number of age-related trends cmerged that were supported by the developmental literature. This study emphasizes the ne't for the development of more refined pragmatic assessment procedures which will aid the collection of normative data presently lacking.
\end{abstract}

\section{OPSOMMING}

n Raamwerk om dic ontwikkeling van gesprekvaardighede, bestaande uit instandhouding en gespreksonderwerp, herstel van kommunikasiebreuk en linguistiese same'hang, in kinders te ondersock, is ontwerp. Dit is bereik deur inligting van hestaande pragmatiese profiele te kombine er met inligting uit literatuu oor onturkkeling. Die raamuerk is ind ukticwelik gemodifiseer om kenmerke, verkry uit data van 12 normaul ontwikkelende Engelssprekende kinders. in dic ouderdomsaroepe drie. vier en vufjaar te akkommodeer. Verskeie ontwikkelingsneigings is opgemerk wat ooreenstem met hevindinge in die ontwikkelingsliteratuur. Hic rdie studie beklemtoon die behoefte aun meer verfunde evaluasieprosedures wat sodoende die versameling van normatitwe data, wat tans ontnerikend is. sal bevorder.

The development of pragmatic language skills has been perhaps the most rapidly expanding area of child language research over the last decade. Much of the work in this area has focused on either communicative intentions (the functions that speech acts serve for the speaker) or the skills involved in conversational competence (including presupposition and the social organization of discourse). However, while the acquisition of communicative intentions has been quite extensively researched (Klecan-Aker \& Swank, 1988), the available information on developing conversational skills, particularly in the pre-school population, is as yet fragmented and sparse.

The absence of adequate baseline data on conversational development in normal communicators has hampered attempts to construct clinically applicable frameworks for assessing the conversational skills of language disordered children. Compounding the difficulty are disagreements over definitions of conversation and the scope of conversational analysis, with a consequent lack of coherent models for studying its development and for developing assessment instruments. Of the commonly available clinical protocols (eg. Prutting \& Kirchner, 1987; Penn, 1985; Roth \& Spekman, 1984; Wollner \& Geller, $1982)$, most comprise categories designed to provide a measure of overall communicative ability and hence lack the specificity required for in-depth analysis of conversation. Further, some were developed explicitly for use with older age groups Penn's (1985) Profile of Communicative Appropriateness for adult populations and Prutting \& Kirchner's (1987) Pragmatic
Protocol for subjects older than 5 years. Wollner \& Geller's (1982) Communication Profile and Roth \& Spekman's (1984) organizational framework for assessing pragmatic skills, although derived from the developmental literature, are plagued by problems of significant gaps in developmental information and have been criticized for their lack of discrete, well-motivated categories of description (McTear \& ContiRamsden, 1989).

A need exists, therefore, for assessment frameworks that focus specifically on conversational competence and that are sensitive to developmental trends in skills in this area in pre-school children. Paired with the need for detailed normative data is the requirement for adequate models of the skills involved in conversation. McTear (1985) observes that models of conversational competence should account for increasing sophistication in three basic areas: (i) topic control (involving turn-taking and the structuring of conversational turns). (ii) repair of conversational breakdown' and (iii) the use of linguistic cohesive devices and presuppositions. He argues that in addition to the accuisition of detailed normative data, more attention should be paid to the validity of descriptive analyses and to providing reliable criteria for the recognition of analytic categories.

Bearing these requirements in mind, the present study was designed as a preliminary attempt to develop a framework for evaluating conversational skills that would reflect developmental trends in the pre-school age group. 


\section{METHODOLOGY}

Aims

1. The development of a framework for the assessment of developing conversational skills in the areas of topic control, repair of communication breakdown and linguistic cohesion.

2. Use of the assessment framework to investigate developmental trends in conversational skills in normally-developing children aged 3 to 5 years.

\section{Procedure}

Procedures for fulfilling the two aims overlapped, in that the assessment framework was further modified to accommodate specific features of the data obtained from normally developing children, in order to ensure its sensitivity to the developmental changes that emerged.

Stage 1: A preliminary assessment framework was devised, by combining selected portions of two existing pragmatic profiles. Penr's (1985) Profile of Communicative Appropriateness (PCA), although developed for use with adult clinical populations, includes three sections (response to interlocutor, control of semantic content and cohesion) which fall within the scope of conversational analysis defined here; these were therefore included in the preliminary framework. Since the PCA does not specifically examine repair of conversational breakdown, Section III ofWollner \& Geller's (1982) Communication Profile, (Communication Breakdown, dealing with repair strategies), was added. Section II (Conversational Acts, dealing with ability to initiate, extend and terminate topics) was also included, with the intention of comparing its usefulness with the corresponding section of the PCA(Control of Semantic Content).

Stage 2: Samples of conversation were collected from 12 nor mally-developing, English-speaking children in three agegroups (see Table 1) attending a creche for Coloured children of Groote Schuur Hospital employees. Both sexes were equally represented. Audiometric and language screening measures were undertaken to ensure normal hearing and language development in all subjects.

\section{Table 1: Subject characteristics}

\begin{tabular}{|c|c|c|c|}
\hline AGE-GROUP & NO. OF S's & MEAN AGE & AGE RANGE \\
\hline 3 years & 4 & 3.6 years & $3.4-3.9$ \\
4 years & 4 & 4.5 years & $4.3-4.7$ \\
5 years & 4 & 5.3 years & $5.1-5.5$ \\
\hline
\end{tabular}

Each subject was audio- and video-taped while conversing individually with the investigator in a familiar room at the creche. Following the suggestion of Brinton et al. (1986) and Mc'Tear (1985), a naturalistic setting was used. 'Tasks used were those which had been established in a prior pilot study (outlined in Rumble, 1988) to be most successful in generating spontaneous conversation: doll play; free conversation on topics initiated by the investigator relevant to the subjects environment and a story re-tell task, following the suggestion of Griffiths et al. (1986) and Liles (1987) who advocate narrative tasks to investigate use of linguistic cohesion devices. Roth \& Spekman's (1984) strategies for creating communication breakdown (mumbling intentionally, responding with a non- contingent reply, providing inadequate or a mbiguous instructions for performing a task) were utilized, a consistent number of times in each subject interaction, at regular points during the conversation.

Data from each subject was orthographically transcribed from the video tapes, including contextual, non-verbal and prosodic information.

Stage 3: The preliminary assessment framework was modified by coding the data obtained from one subject in each age group according to the categories of the preliminary framework. Modifications were necessitated by difficulties related to the use of different scoring and coding systems for sections of the framework obtained from different sources. Furthermore, expansion, re-ordering and omission of certain categories was necessary to reflect subtle developmental trends. Information from the developmental literature was consulted for this purpose and included in the final framework.

Thus, an inductive process was employed whereby descriptive categories evolved out of information reported in the literature and were subsequently modified to accommodate features that emerged from the data. 'The information was organized into a single framework comprising the superordinate categories of topic control, repair of communication breakdown and linguistic cohesion.

Stage 4: Data from all 12 subjects was coded and analyzed to the final assessment framework. All utterances were coded for the linguistic cohesion and repair of breakdown sections, whereas only those produced during the free conversation task were coded for the topic control section. For the latter section, the investigator's utterances were also coded. Coding of data was undertaken independently by two trained speech and language pathologists from observation of the videotapes. Both raters were familiar with the defining criteria for recognition of categories. Point to point inter-rater reliability was calculated at $80 \%$, above Silverman's (1977) criterion of $75 \%$.

Frequencies of occurrence of each ca tegory were calculated for each-subject. These frequency scores were then subjected to one-way Analysis of Variance tests to determine if differences between these frequencies were statistically significant.

\section{RESULTS AND DISCUSSION}

The categories of conversational skills that emerged in the process of developing a final assessment framework are shown in Tables 2,3 and 4. Discussion of the specific modifications and expansions of categories undertaken in developing and refining the original descriptive categories to accommodate the developmental data is not within the scope of this paper. A description of these processes, together with full definitions and examples of all categories in the final framework is provided in Rumble (1988). The discussion here will focus on the developmental data gathered from the normally developing subjects.

Tables 2, 3 and 4 also provide, for each age group, the mean frequencies of occurrence of the categories of conversational skills in each section of the framework. Few of the comparisons of frequencies across age groups yielded statistically significant results, presumably due, at least in part, to the small sample size which magnifies the effects of individual variation on overall comparisons. Déspite this, a number of developmental trends were evident; these are discussed below for each section of the framework. 


\section{TOPIC CONTROL.}

1. Initiatory Acts (IA): Table 2 shows that 3 and 4 year olds initiated a greater number of topics overall than did the 5 year olds, a trend also reported by Wanska \& Bedrosian (1985) However, at least half the IAs produced by all subjects were inappropriate, as they occurred where responses to previous turns were expected. Both Prutting( 1979) and McTear (1985) note that children from 2 to 3 years exhibit problems main taining and extending the topic of conversation, resulting in inappropriate and rapid changes of topic throughout their discourse. The drop in number of topic initiatory acts after 4 years may thus reflect an increasing ability to use more appropriate strategies for topic maintenance, with a corresponding decreasing dependency on initiatory acts to serve this function.

Table 2: Mean frequency scores per age group for the categories of topic control

\begin{tabular}{|l|c|c|c|}
\hline & \multicolumn{3}{|c|}{ Age group } \\
Category & 3 years & 4 years & 5 years \\
\hline Initiatory Act & & & \\
Investigator & 5.0 & 6.5 & 6.25 \\
Subjects & 4.5 & 4.5 & 2.5 \\
\hline $\begin{array}{l}\text { Topic Relevant } \\
\text { Response }\end{array}$ & & & \\
$\begin{array}{l}\text { Investigator } \\
\text { Subjects: }\end{array}$ & 32.75 & 38.0 & 30.0 \\
$\begin{array}{l}\text { Verbal Acknowledge- } \\
\text { ment }\end{array}$ & & & \\
$\begin{array}{l}\text { Verbal Response to } \\
\text { Interrogative }\end{array}$ & 15.25 & 19.0 & 22.25 \\
$\begin{array}{l}\text { Nonverbal Acknowledge- } \\
\text { ment }\end{array}$ & 3.5 & 3.5 & 1.5 \\
$\begin{array}{l}\text { Nonverbal Response } \\
\text { to Interrogative }\end{array}$ & 19.75 & 8.5 & 6.5 \\
\hline Topic Relevant Act & & & \\
Investigator & 37.5 & 33.5 & 32.75 \\
Subjects & $9.0^{*}$ & $26.75^{*}$ & $14.75^{*}$ \\
\hline $\begin{array}{l}\text { Off Topic Act } \\
\text { Inappropriate } \\
\text { Response } \\
\text { No Response }\end{array}$ & & & \\
\hline $\begin{array}{l}* \\
\text { year groar group produced (p=0.05) }\end{array}$ & significantly more than 3 \\
\hline
\end{tabular}

2. Topic Relevant Responst's (TRR): These occur in response to an utterance of the previous speaker. Table 2 shows that for subjects in all three age groups, a far greater proportion (90\%) of TRRs were responses to interrogatives, rather than acknowledgements of previous turns, a finding supported by Bloom et al. (1976) and McTear (1985). The tendency for adults to rely heavily on interrogatives in dialogue with young children is well documented (Corsaro, 1979) and may serve to facilitate conversational development by providing the child with opportunities to provide linguistically contingent replies, thus keeping the conversational ball in play.
Table 2 also shows that subjects' use of verbal TRRs increased from 3 to 5 years, while the frequency of non-verbal 'TRRs declined, reflecting an expanding linguistic competence and a corresponding diminishing reliance on non-linguistic modes of response to maintain discourse topics.

3. Topic Rclevant Acts (TRA): These are spontancous utterances that go beyond the previous turn by adding new information of relevance to the topic. Table 2 shows a higher occurrence of TRAs in the 4 and 5 year old groups, with the increase from 3 to 4 years being statistically significant. Many more TRAs were produced by the investigator in all age groups, a trend also noted by Corsaro (1979) who observed that adults generally respond to children's utterances with TRAs, while children tend to respond to adults' TRAs with TRRs. The number of investigator-TRAs diminished with olde subjects who provided greater numbers of 'I'RAs themselves.

4. Off Topic Arts - either inappropriate responses to questions or failure to respond where a response was expected showed a general tendency to diminish with age, corresponding to the increase in appropriate verbal responses to interrogatives.

5. Mean number of utterances per turn: In interactions with all age groups, the investigator produced a greater number of utterances per turn than subjects.

The data on topic control generally confirmed McTear's (1985) observation that from 3 to 5 years the major development is from relatively closed exchanges with an initiaterespond structure to more extended sequences of dialogue. By 5 years of age the children here showed increased ability to maintain and extend a topic of conversation in the form of topic relevant acts and responses. Yet, even at this age, the adult remained the dominant member of the communicative dyad, taking responsibility for topic control in the form of a high number of interrogatives and extensions of the child's utterances (TRAs) to ensure shared meaning, as well as producing an overall greater quantity of utterances at each turn.

\section{REPAIR OF CONVERSATIONAL, BREAKDOWN}

1. Clarification requests: Some clear patterns emerged here with regard to a sequence of development. As Table 3 shows, requests for clarification were just beginning to emerge in the 3 year old group, supporting both Gallagher (1977) and Garvey's (1979) observation that children do not produce contingent queries until 3 years of age. Clarification requests were produced incrementally by one 3 year old, two 4 year olds and all five year olds. First to emerge, at 3 years, were specific requests for confirmation, where the child requests confirmation of some element of the previous utterance about which he is uncertain, as in the following example.

I : 'pass me another chair

$S:$ this (S holds up chair)

$\mathrm{I}:$ yès

Non-specific requests for repetition emerged at 4 years; like specific requests for confirmation, these do not specify which part of the previous utterance needs to be clarified:

I : 'give me another one

S: h $\widehat{h m m}$

I : 'pass me another chair 
Table 3: Mean frequency scores per age group for the categories of repair of conversational breakdown

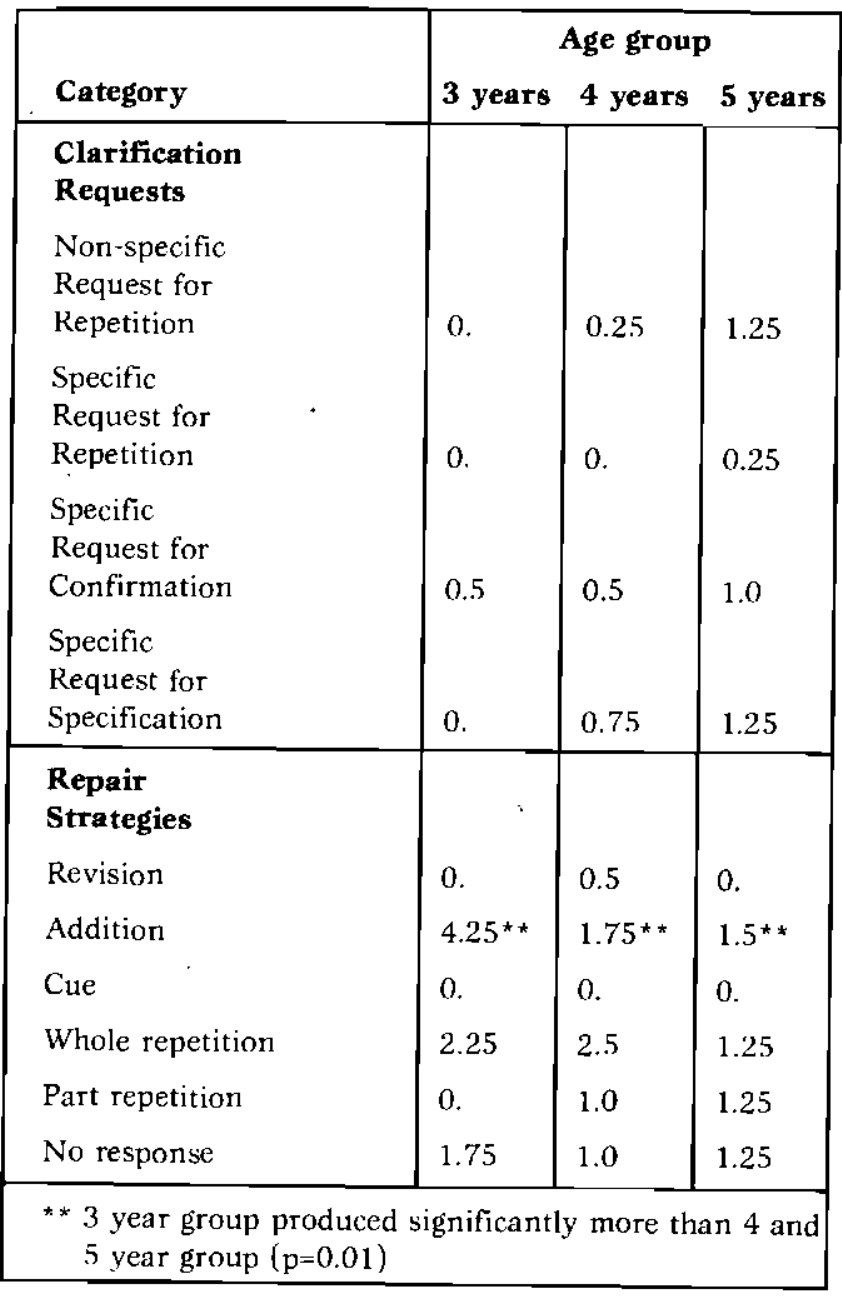

More demanding linguistically are requests that require identification of specific ambiguous or missing information, as in specific requests for specification and specific requests for repetition. The former emerged at 4 years and is illustrated in the following example.

\footnotetext{
1 : those 'people who came to your creche that were 'telling you stories

S : what people
}

The latter was produced only once, by a 5 year old subject:

I : put the "cat in the box

$S$ : the (pause 2 seconds) (S looks questioningly at I) .

I : càt

2. Repair strategies: As is evident from Table 3, the developmental picture with regard to use of repair strategies in response to requests for clarification was less clear, as subjects showed a fairly high degree of variability and inconsistency in their use of these strategies. Nevertheless, certain strong tendencies emerged.

3 year olds produced a significantly greater number of addition repairs (involving addition of information not provided in the original utterance) than 4 or 5 year olds. The relative linguistic immaturity of this age group may account for this : 3 year olds frequently produced utterances containing either insufficient information or inappropriate anaphoric and demonstra tive reference (discussed below), necessitating a large number of clarification requests for additional information, as the following example shows.

I : 'what was the mommy saying here

$\mathrm{S}$ : birthday

I : whòse birthday

$S$ : the girl's birthday

Whilst the frequency of addition repairs declined in the older age groups, 4 and 5 year olds most frequently used repetition repairs, involving repetition of the whole or part of a previous utterance. The trend here, shown in Table 3, was for a decrease in whole repetitions and an increase in part repetitions with increasing age, reflecting a growing ability to distinguish which specific linguistic elements require repeating. Adults may play a facilitative role in this process : the majority of part repetitions in the data were produced in response to specific requests for specification which assist the child in determining which elements need clarification.

Revision repair is a more complex linguistic strategy than repetition or addition, involving recoding of the message in the form of alterations to syntactic structure; these were used by only one child, a 4 year old. No examples of cues (involving definition of terms from the original utterance or providing relevant background information for its interpretation) occurred, suggesting that these require a level of metalinguistic abstraction that is beyond the 5 year old level.

To summarize, the findings suggest that the development of effective strategies for dealing with conversational breakdown depends at least in part on the ability to identify specific information bearing elements of a message. This ability did not begin to manifest in either clarification requests or repair strategies before 4 years of age, although repair strategies were certainly in evidence in younger children of 3 years. Further, it seems the ability to recode surface syntactic or lexical aspects of the message in formulating repairs is a skill developed only from 5 years and beyond.

\section{LINGUISTIC COHESION}

1. Anaphoric Reference: This category comprises pronouns that refer to previously identified referents. They were coded as appropriate when in terpretable either with the aid of contextual cues or due to the referent having been previously identified. Table 4 shows that many more instances of anaphoric reference used by subjects were appropriate than inapprop. riate and that appropriate use increased with age. However, many of the appropriate instances may have been considered inappropriate in the absence of contextual cues to aid the investigator's interpretation.

Appropriate use of pronouns is closely linked to the ability to make correct assumptions regarding givén versus new information. Bates \& MacWhinney (1979) point out that inappropriate use of pronouns (ie. without prior identification of the referent) does not necessarily imply lack of awareness that pronouns specify given information, bút rather that the child makes incorrect assumptions about the 'givenness' of information. In the data reported here, such incorrect assumptions were found in all age groups. Further, the use of rising intona- 
Table 4: Mean frequency scores per age group for the categories of linguistic cohesion

\begin{tabular}{|l|c|c|c|}
\hline & \multicolumn{3}{|c|}{ Age group } \\
Category & 3 years & 4 years & 5 years \\
\hline $\begin{array}{l}\text { Anaphoric Reference } \\
\text { appropriate } \\
\text { inappropriate }\end{array}$ & 16.25 & 27.5 & 28.75 \\
\hline $\begin{array}{l}\text { Demonstrative } \\
\text { Reference } \\
\text { appropriate } \\
\text { inappropriate }\end{array}$ & 5.5 & 21.25 & 9.25 \\
\hline $\begin{array}{l}\text { Substitution } \\
\text { appropriate } \\
\text { inappropriate }\end{array}$ & 22.5 & 18.5 & 23.25 \\
\hline $\begin{array}{l}\text { Ellipsis } \\
\text { appropriate } \\
\text { inappropriate }\end{array}$ & 2.0 & 2.0 & 1.0 \\
\hline $\begin{array}{l}\text { Additive } \\
\text { conjunction }\end{array}$ & 11.75 & 2.75 & 0.25 \\
\hline $\begin{array}{l}\text { Causal } \\
\text { conjunction }\end{array}$ & $15.25 *$ & $23.0^{*}$ & $27.5 *$ \\
\hline $\begin{array}{l}\text { Temporal } \\
\text { conjunction }\end{array}$ & 6.75 & 3.0 & 3.75 \\
\hline $\begin{array}{l}\text { Antithesis } \\
\text { conjunction }\end{array}$ & 1.0 & 3.0 & 1.25 \\
\hline * 5 year group produced & $5 i g n i f i c a n t l y$ & \\
3 year group (p=0.05) & 1.0 & 4.75 & 6.5 \\
\hline
\end{tabular}

tion accompanying information that the child assumed was shared was a feature used consistently by all subjects. This is illustrated in the following example from a 5 year old who incorrectly assumed that the investigator knew who the mem. bers of her household were.

I : so 'who lives in your house then

$\mathrm{S}: \widehat{\mathrm{we}}$

I : who's wेe

$S: \emptyset$ (S looks puzzled)

2. Demonstrative Reference: This refers to the use of deictic terms such as 'this', 'that', 'here', 'there', which refer to referents by specifying their location on the dimension of distance. Table 4 indicates that subjects in all age grouips had attained the ability to encode these deictic relations linguistically. The vast majority of instances of demonstrative reference were apropriate, with inappropriate use (where the referent was not clear from the context) decreasing slightly at 5 years. These findings are consistent with the observations of both Bloom et al. (1976) and Bates \& MacWhinney (1979) that children as young as 3 years show awareness of deictic shift by correct use of demonstrative pronouns.

3. Ellipsis: Use of elliptical utterances allows the speaker to reduce redundancy in a message by encoding only the essential elements; it therefore relies on the ability to identify given information in prior messages which can then be deleted in the elliptical utterance. Table 4 shows that appropriate ellipsis was present from 3 years, its use increasing significantly with age while inappropriate use declined.

These trends were closely associated with type of ellipsis. Clausal ellipsis (involving ellision of both noun and verb phrase) results in encoding of minimal information; this occurred with greater frequency in all age groups than either nominal or verbal ellipsis. A large amount of inappropriate clausal ellipsis occurred in the data from 3 year olds, who were unaware that further specification was necessary. The use of appropriate nominal and verbal ellipsis increased with age, often prompted by specific requests for specification from the investigator. Their use appears to coincide with the development of increasing ability to take the listener's needs into account and consequently to select the appropriate elements of a message to encode.

4. Substitution: This category refers to items other than personal pronouns which replace previously identified elements. As is evident from Table 4 , the data here suggests that correct use of substitution is possibly a later acquired form of alternative coding then ellipsis. Only two 3 year olds used substitution appropriately whereas all of them used appropriate ellipsis and far fewer appropriate instances of substitution than ellipsis occurred overall for the whole subject group.

All instances of substitution in the data were nominal (one word substituting for a noun phrase), except for one example of verbal substitution (one word substituting for a verb phrase), produced by a 5 year old. Thus verbal and clausal substitution may be more complex forms acquired only after 5 years.

5. Conjunction: Conjunctions serve a cohesive function in discourse when they relate successive utterances to each other across speaking turns. Ervin-Tripp (1978) described a tentative sequence of development of conjunction use across turns: additive (and, too, also) followed by temporal (then), causal (so, because), and then antithesis (but). The frequencies shown in Table 4 for conjunction use replicate this sequence exactly. Additive conjunctions were used more frequently than any other type by all age grou'ps; this is in accordance with McTear's (1985) observation that a 5 year old's 'and' is still the main cohesive conjunction used.

An interesting feature of these subjects' conjunction usàge which is not reported elsewhere in the literature, however, was the use of 'now' (as well as 'and') to express additive relations and 'so' to express temporal relations, as shown in the following examples.

$$
\begin{aligned}
& \text { I : That's the shower } \\
& \mathrm{S}: \text { now 'where's the táp (additive) } \\
& \mathrm{I}: \text { now 'what happens next } \\
& \mathrm{S}: \text { so the 'pram ride by itself (temporal) }
\end{aligned}
$$

These features are assumed to be a feature of the dialect of English spoken by the subjects,since they were used by all the children in this study.

To summarize, the data on cohesion indicated that correct use of all types of cohesive devices investigated was present to some degree from 3 years of age, with a general trend for 
increasing apropriate use and a decrease in inappropriate use up to 5 years. Developing competence in the use of cohesive devices seemingly involved the ability to scan prior messages, make correct assumptions regarding the need for new as opposed to given information and to take the listener's perspective into account.

\section{CONCLUSION}

This study has emphasized the need for the development of more refined procedures for assessing conversational skills in children, as well as for the collection of normative data. The procedure employed here, of collating descriptive categories from previous research and modifying these inductively to accommodate features of the data collected from normally developing children, proved useful in ensuring that the resultant categories were adequately motivated in terms of their relevance to developing language. Further, the use of small subject samples in successive age levels, while raising problems of generalizability, allowed for detailed descriptive analysis of relatively subtle developmental trends. Given the paucity of present knowledge about the development of conversation, this approach may be preferably to a more superficial analysis of larger samples.

It would certainly be premature at this stage to consider the framework provided here as a clinically applicable tool McTear (1985) rightly cautions that we are a long way off from being able to produce profiles of conversational development on analogy with similar existing profiles for areas such as syntax and phonology. We would suggest that a great deal more groundwork is required in the form of careful refinement of descriptive categories on the basis of developmental information. Additionally, several problematical theoretical and methodological issues require attention if the goal of an effective clinical tool is to be realized. For one thing, findings from naturalistic methods of data collection, such as that used in this study, are invariably limited by the fact that conclusions are drawn regarding subjects' linguistic competence on the basis of their performance in a limited and particular sample of interaction. Thus, further research efforts to validate the descriptive categories derived here should include systematic exploration of the effects on performance of contextual factors such as variations in communicative partner and physical setting. It seems likely, for instance, that important differences may exist between adult-child and child-child discourse. Future research will also need to address the issue of how best to 'score' categories of conversational behaviour in clinical assessment; as McTear \& Conti-Ramsden(1989) point out, both frequency counts andijudgements of appropriacy are problematical as indices of conversational analysis. Finally, it is possible that descriptive categories based on normal develop- ment may not be sensitive to specific problems that arise in language disorder, suggesting the need for testing the assessment framework with language impaired children.

\section{REFERENCES}

Bates, F. \& MacWhinney, B.A. A functionalist approach to the acquisition of grammar. In E. Ochs and B.B. Schieffelin (Eds.) Developmental Pragmatics. New York: Academic Press, 1979.

Bloom, L., Rocissano, L. \& Hood, L. Adult-child discourse: developmental interaction between information processing and linguistic knowledge. Cognitive Psycholosy, 8, 521-522, 1976.

Brinton, B., Fujiki, M., Winkler, E. \& Loeb, D.F. Development of conversational repair strategies in response to request for clarification. J. Speech Hear. Res., 29, 75-81, 1986.

Corsaro, W.A. Sociolinguistic patterns in adult-child discourse. In E. Ochs \& B.B. Schieffelin (Eds) Developmental Praymatics. New York: Academic Press, 1979.

Frvin-Tripp, S. Some features of carly child-adult dialogues. Language in Society. 7, 357-73, 1978.

Gallagher, T.M. Revision behaviours in the speech of normal children developing language. J. Speech Hear. Res., 20, 303-318, 1977.

Garvey, C. Contingent queries and their relations in discourse. In E. Ochs \& B.B. Schieffelin (Eds) Developmental Prapmatics. New York: Academic Press, 1979.

Griffith, P.1., Ripich, P.N.\& Dastoli, S.L. Story structure, cohesion and propositions in story recalls by learning disabled and nondisabled children. Journal of Psycholinguistic Research, I5(6), 539-555, 1986.

Klecan-Aker, J.S. \& Swank, P.R. The use of a pragmatic protocol with normal preschool children. J. Comm. Dis, 21, 85-102, 1988.

Jiles, B.Z. Episode organization and cohesive conjunctives in narratives of children with and without language disorder. J. Speech Hear. Res., 30(2), 185-196, 1987.

McTear, M.F. Children's Conversation. Oxford: Basil Blackwell, I985.

McTear, M.F. \& Conti-Ramsden, G. Assessment of pragmatics. In K. Grundy (Ed.) Linguistics in Clinical Practice. Taylor and Fran. cis, 1989.

Penn, $C$. The profile of communicative appropriateness: a clinical tool for the assessment of pragmatics. South African Journal of Com munication I Disorders, 32, 18-25, 1985.

Prutting, C.A. Process: the action of moving forward progressively from one point to another on the way to completion. J. Speech Hear. Dis., 44(1), 3-30, 1979

Prutting, C.A. \& Kirchner, D.A. A clinical appraisal of the pragmatic aspects of language. J. Speech Hear. Dis., 52, 105-119, 1987.

Roth, F.P. \& Spekman, N.J. Assessing the pragmatic abilities of child ren. Part I: Organization framework and assessment parameters. J. Speech Heur. Dis., 49, 2-11, 1984.

Rumble, $\mathrm{S}$. The development of a frumework for assessing children's con' versutional skills and its use in a preliminary investigation into developmental trends in normal three, four and five year olds Unpublished research report, Department of Logopaedics; University of Cape 'Town, 1988.

Silverman, S. Research Design in Speech Pathology and Audiology. New Jersey: Prentice-Hall, 1977.

Wanska, S.K. \& Bedrosian, J.L. Conversational structúre and topic! performance in mother-child interaction. J. Speech Hear. Res., $28,579-584,1985$.

Wollner, S. \& Geller, E. Methods of assessing pragmatic abilities. In J.V. Irwin (Ed) Pragmatics: The Role in Language Development. University of Laverne: Fox Point Publishing, 1982. 